\title{
Cruise ship pathologies in remote regions
}

\author{
Mathieu Carron ${ }^{1}$, Nicolas Emeyriat ${ }^{1}$, Jacques Levraut ${ }^{1}$, Nicolas Blondeau ${ }^{2}$ \\ ${ }^{1}$ Emergency Department, Centre Hospitalier Universitaire de Nice, Nice, F-06001, France \\ 2Université Côte d'Azur, CNRS, IPMC, Sophia Antipolis, F-06560, France
}

\begin{abstract}
Background: Navigations on cruise ships are rising and tend to spread to remote areas like polar regions. Our aim was to assess the prevalence of pathologies encountered on a cruise ship navigating in remote areas including Polar Seas.

Materials and methods: A prospective observational, descriptive and cross-sectional study was conducted aboard a cruise ship with an overall capacity of 200-264 passengers and 140 crewmembers, sailing in remote areas as the Arctic Ocean and the Antarctic Peninsula over a period of 205 days. The database was built on all first consultations for passengers and crewmembers done by the onboard physician. Each symptom and diagnosis was coded according to the "International Classification of Primary Care, $2^{\text {nd }}$ edition". For statistical analysis, the quantitative data were expressed as mean \pm standard deviation and qualitative data as percentages. The percentages were compared using a $\chi^{2}$ test corrected according to the Yates' method or by a Fisher test when appropriate.

Results: A total of 446 diagnoses were studied on the 910 consultations originally included (13.7\% of the people on board). The median age for the passengers and the crewmembers was respectively 68 (age ranging from 12 to 90) years and 31 (18-62) years. Likewise, the sex ratio (male/female) was 0.98 and 3.23. Infectious diseases were predominant (prevalence of 43.7\%). Among them, respiratory infections were the most common and gastroenteritis seemed to be more frequent in passengers (prevalence of $11.5 \%$ vs. $5 \%, p=0.10$ ). Cutaneous pathologies were more frequent in crewmembers (prevalence of $26.6 \%$ vs. $18.7 \%, p=0.04$ ) and allergic dermatitis was the second most frequent in this group of patients (prevalence of $7.2 \%)$. Cardiovascular diseases, more common in passengers $(p=0.05)$, represented $4 \%$ of all diagnoses. Two cases of phlebitis, one stroke and one subacute heart failure were diagnosed. Among traumatic injuries, cutaneous traumas were the commonest (prevalence of 76.5\%). Musculoskeletal traumas were more common in passengers $(p=0.04)$. An acute gastrointestinal haemorrhage required a medical evacuation from the Antarctic Peninsula.

Conclusions: The physician should be prepared to face emergency cases by developing personal expertise specific to maritime medicine in remote areas. Highlighting the particularity of cases handled in remote areas, our results should also pave the way of the development of medical protocols for ships lacking physician.
\end{abstract}

(Int Marit Health 2018; 69, 2: 75-83)

Key words: cruise ship, illness, Antarctica, passengers, crewmembers, remote regions

\section{INTRODUCTION}

Nowadays, navigations on modern cruise ships are considerably increasing [1]. We are witnessing changes in their size and capacity that is often over several thousand including passengers and crewmembers and in their navigational areas that tend spreading to remote areas. This may raise new sanitary/health issues because most of these remote regions offer difficult access and complicated sanitary evacuation process. A striking example is the polar circle that became over the past decade a prized destination for several touristic cruises [2, 3]; this includes the southern and northern polar circles as well as the Northwest Passage that global warming has opened to navigational [4-7]. In addition, such cruise ships may encounter rough sea and 


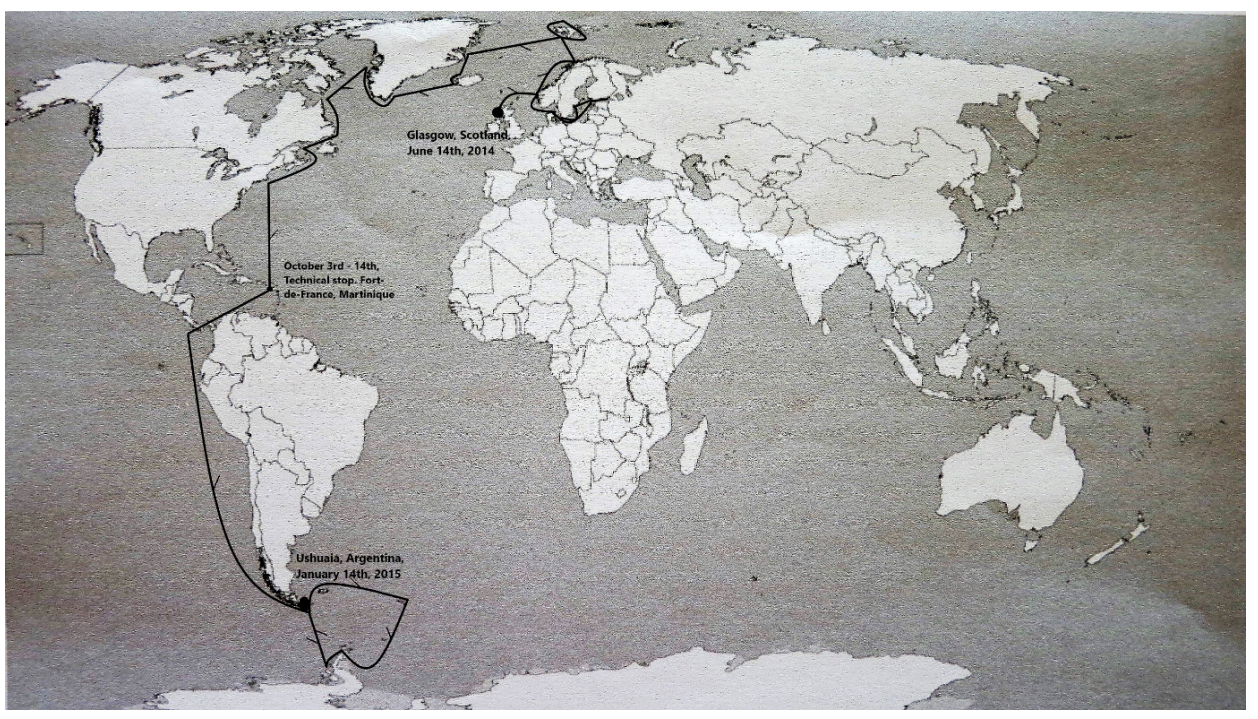

Figure 1. The ship navigation map

climatic conditions far from the coastline, especially during transoceanic sailings jeopardising the immediate assistance of their passengers. Among them, while all the age groups are represented, there is often a high number of elderly [8-10] who present a higher risk of developing pathologies [11]. Therefore, different pathologies as well as emergencies can occur during these journeys and the physician and nurse have to be better prepared to manage them to provide the best care to the persons on board. To ensure the quality of care on board French ships, a specific medical supply must be closely followed. Several retrospective studies investigated illnesses and injuries occurring among cruise ships passengers [8, 10, 12] and to the best of our knowledge, only one prospective study that monitored the whole population on board was conducted during a world cruise [13]. Some of them mainly focused on respiratory and digestive infections, which are the most commonly occurring on cruise ships. Therefore it is important to provide more epidemiologic data to improve the quality of the health management on board and our study aimed to assess the prevalence of pathologies encountered on the whole population of a cruise ship navigating in remote areas.

\section{MATERIALS AND METHODS}

This prospective observational, descriptive and cross-sectional study was conducted on the whole onboard population of a small cruise ship (length: 466 feet, beam: 59 feet, tonnage: 10,700 and 6 decks), with an overall capacity of 200 to 264 passengers per cruise, occupying 132 cabins, and $140( \pm 5)$ crewmembers. For expedition cruises in Arctic and Antarctic territories, the number of passengers was limited to 200. The onboard population was international. The crewmembers were principally French, Indonesian, Filipino, Romanian, Mauritian, and Bulgarian.
The study was performed by the onboard physician during his two embarkations, respectively from the $14^{\text {th }}$ of June 2014 to the $3^{\text {rd }}$ of October 2014, and from the $14^{\text {th }}$ of October 2014 to the $14^{\text {th }}$ of January 2015 . Between these two periods of evaluation, the ship was in technical stop without passengers and medical team on board, and at with least half of the crew ashore.

The navigation area was estimated as being remote areas as it was accomplished in Antarctica and Arctica, including North-South navigations to reach these polar territories. It covered over several thousand nautical miles across 9 oceans/ /seas. The ship spent 1 month around the Baltic Sea and then sailed across the Arctic Polar Circle during 2 months, starting from Tromso in Norway, to reach Quebec in Canada on the $18^{\text {th }}$ of September. The ship sailed south to the Caribbean Sea, throughout the Panama Channel and sailed down along the coast of South America to reach Ushuaia in Argentina on the $15^{\text {th }}$ of November. From that moment on and until the $14^{\text {th }}$ of January 2015, the ship (after departure from Ushuaia) sailed across the Drake Passage to reach successively: Falkland Islands, South Georgia and the Antarctic Peninsula. Thus the longest time at sea was 15 straight days in the Southern Polar Seas (see the ship navigation map - Fig. 1).

All the different types of onboard consultations were included in the database; independently of the localisation (hospital, cabin, common areas of the ship as well as during the ashore excursions) and timing they were performed. Consultations by crewmembers that occurred during the two positioning of the ship (that lasted 7 days) were including despite this manoeuvre was realised in absence of passengers. Finally, consultations conducted solely by the nurse were not included in the study. Overall, the medical staff on board comprised one physician and one 
nurse (two different nurses in two embarkations). The study focused on the first consultation of the physician to avoid selection bias by artificially increasing the prevalence of a pathology that requires daily medical follow-up. Therefore, follow-up consultations were excluded from the database that was built daily from the medical file at the end of the day. The medical files were collected for crewmembers and passengers in two distinct and comparable databases with identical variables and subjected to statistical analyses after completion of the cruise. A clear distinction between the "reason" (the symptoms resulting in medical consultation) and the "result" (physician's diagnosis at the end of the consultation) of the consultation was done. Since for each patient the medical examination could result in several putative diagnoses the database includes an unequal number of patient and "consultation results" with a higher number of diagnoses than registered patients.

Each symptom and diagnosis was recorded in a verbatim quote and was next coded according to the "International Classification of Primary Care, $2^{\text {nd }}$ edition" (ICPC-2) [14]. The ICPC- 2 is divided into 17 chapters and 7 components. To focus on the confirmed diagnoses, we had to exclude from the study the overall component "Symptoms and complaints". Nevertheless, the particularity of the navigation area in polar region imposed to take in consideration the component "A02, Chills" for hypothermia cases. In the chapter "General and unspecified", diagnoses from the component "Other diagnoses" were excluded because they referred to occupational medicine, public health, or neonatal medicine, with the exception of the following two items:

- "A92, Allergy", to include any general allergy and anaphylactic shock;

- "A96, Death", to include any death on board.

We also codified seasickness by "N99, Neurological disease, other" because the digestive symptoms of seasickness due to vertigo result from a disorder between vision and the inner ear [15] and the ICPC-2 proposes neurological coding for vertigo. In our database, the coding "N99" identifies only seasickness cases.

\section{STATISTICAL ANALYSIS}

For statistical analysis, the quantitative data are expressed as mean \pm standard deviation and qualitative data as percentages. The percentages were compared using a $c^{2}$ test corrected according to the Yates' method or by a Fisher test when appropriate. A p value of less than 0.05 was considered as statistically significant.

\section{RESULTS}

Data collection took place over a period of 6 months and 3 weeks during the 205-day trip achieved in 19 cruises and 2 ship positioning. During the full cruise duration, 6640 peo- ple, including 3698 passengers and 2942 crewmembers, embarked on board. The number of initial consultations was 910 accounting for $13.7 \%$ of the people on board. Among them, we selected 702 medical consultations according to the criteria described in the 'Materials and methods' section (312 for the passengers and 390 for the crew members). This number represents $10.6 \%$ of all the incoming persons identified in the official list of the cruise line and more specifically $8.4 \%$ of passengers and $13.25 \%$ of crew members $(p<0.0001)$. Out of them, a total of 446 diagnoses were analysed in the present study: 222 for the crewmembers and 224 for the passengers (Fig. 2). The median age was 68 (age ranging from 12 to 90 ) years for passengers and 31 (18-62) years for the crew. Overall, the median age was 44 years (12-90). The sex ratio (male/female) was 0.98 for passengers and 3.23 for crewmembers. The whole population had a sex ratio of 1.81 .

Most of the common illnesses on board were infectious pathologies (Table 1) with a prevalence of $43.7 \%$. Among them, respiratory infections were predominant (prevalence of $63.6 \%$ ). Upper respiratory infections were the main diagnosis in the whole population. The respiratory diseases comprised the most common diagnosis with a prevalence of $28.7 \%$ (Table 2).

Cutaneous pathologies were the second most frequent medical problem encountered on board (prevalence of $22.6 \%$ ). They were significantly more frequent among crewmembers (Table 2). In addition, skin diagnoses, unrelated to the components "Infections" and "Injuries" of the ICPC-2, were much more prevalent in the crew than in the passengers: the prevalence was of 21.1 and 6.8 , respectively $(p=0.006)$. Indeed, it is worth noting that atopic and contact dermatitis was the second most frequent diagnosis for crewmembers (Table 3). Table 4 shows the first 10 diagnoses for the passenger population.

Although cardiovascular diseases were only part of the "Other diagnoses", they represented $4 \%$ of the onboard diagnoses and were significantly more common in passengers. The arterial hypertension was the main diagnosis. Two cases of phlebitis were diagnosed and treated on board, one of which was confirmed by an ultrasound examination performed on land. A stroke was diagnosed in a passenger who experienced sudden onset dysarthria during a sport session. It required a medical evacuation to the Lunenburg Emergency Department in Canada, Nova Scotia. One case of subacute heart failure secondary to pneumonia and one case of cardiac angina were also diagnosed.

Traumatic injuries resulting in accident reports tend to be more frequent in passengers, although the number of traumatic injuries reported among the crew was not statistically different. The majority of these cases were cutaneous 


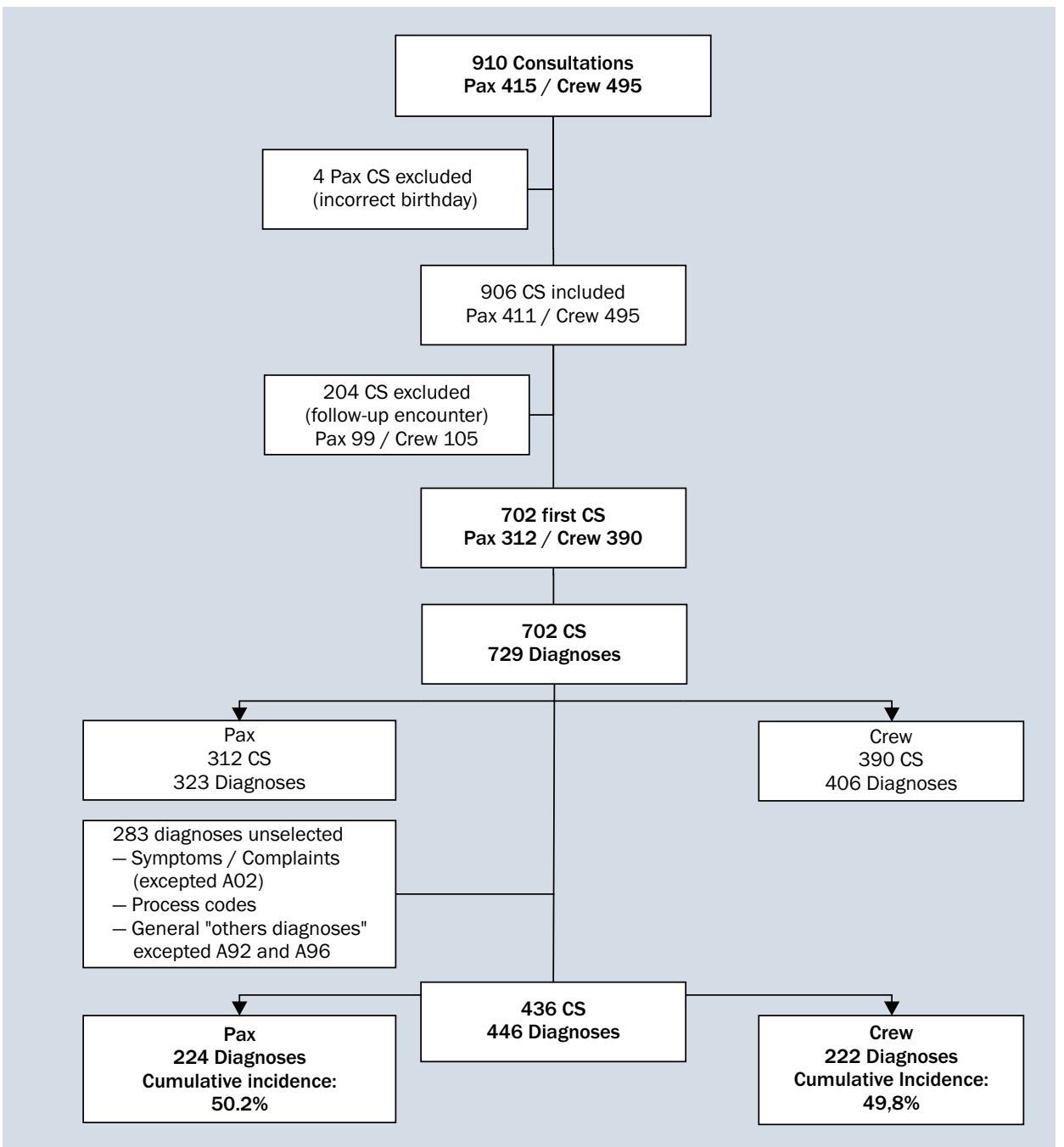

Figure 2. Flow chart summarising the path of selection of passenger and crewmember consultations included in the study; CS - consultations; Pax - passengers, Crew - crewmembers

Table 1. Classification of diagnoses according to the components of the ICPC-2

\begin{tabular}{lllll}
\hline Components & $\begin{array}{l}\text { Passengers } \\
\text { 224 diagnoses } \\
\mathbf{n} \text { (100) }\end{array}$ & $\begin{array}{l}\text { Crewmembers } \\
\text { 222 diagnoses } \\
\mathbf{n}(\mathbf{1 0 0})\end{array}$ & $\mathbf{P}$ & $\begin{array}{l}\text { Total out of 446 } \\
\text { diagnoses } \\
\mathbf{n} \text { (100) }\end{array}$ \\
\hline Infections & $96(49.2)$ & $99(50.8)$ & 0.71 & $195(43.7)$ \\
Other diagnoses & $87(47.8)$ & $95(52.2)$ & 0.39 & $182(40.8)$ \\
Injuries & $38(59.4)$ & $26(40.6)$ & 0.11 & $64(14.4)$ \\
Others* & $3(60)$ & $2(40)$ & 1 & $5(1.1)$
\end{tabular}

*Symptoms, complaints/neoplasms/congenital anomalies

traumas, with an overall prevalence of $76.5 \%$ (68.4\% for passengers; $88.5 \%$ for crew members; $p=0.12$ ). Most of them consisted in basic skin wounds. Though, a case of grade $2 \mathrm{~A}$ burn in both hands occurred in a crewmember during navigation to Spitzbergen. Musculoskeletal traumas were also more common in passengers. Their prevalence was of $26.3 \%$ for passengers and $3.8 \%$ for crewmembers $(p=0.04)$. The mild sprains predominated. The proportion of other traumas was not high enough to emerge in the first 10 diagnoses. Finally, some fractures happened ashore. A 57-year-old female passenger had a fracture of the upper end of the femur following a fall that happened ashore because of violent gusts of wind in Puerto Natales, Patagonia. A fracture of lower end of the tibia occurred 
Table 2. Classification of diagnoses according to the chapters of the ICPC-2

\begin{tabular}{lllll}
\hline Chapters (Coding) & $\begin{array}{l}\text { Passengers } \\
\mathbf{n} \text { (100) }\end{array}$ & $\begin{array}{l}\text { Crewmembers } \\
\mathbf{n}(\mathbf{1 0 0})\end{array}$ & $\mathbf{P}$ & $\begin{array}{l}\text { Total } \\
\mathbf{n} \text { ( 100) }\end{array}$ \\
\hline Respiratory (R) & $61(27.2)$ & $67(30.2)$ & 0.49 & $128(28.7)$ \\
Skin (S) & $42(18.7)$ & $59(26.6)$ & 0.04 & $101(22.6)$ \\
Digestive (D) & $27(12.1)$ & $26(11.7)$ & 0.91 & $53(11.9)$ \\
Musculoskeletal (L) & $24(10.7)$ & $22(9.9)$ & 0.78 & $46(10.3)$ \\
Neurological (N) & $20(8.9)$ & $4(1.8)$ & 0.0008 & $24(5.4)$ \\
Cardiovascular (K) & $13(5.8)$ & $5(2.2)$ & 0.05 & $18(4.0)$ \\
Eye (F) & $6(2.7)$ & $12(5.4)$ & 0.14 & $18(4.0)$ \\
General (A) & $9(4.0)$ & $6(2.7)$ & 0.44 & $15(3.4)$ \\
Urological (U) & $6(2.7)$ & $5(2.2)$ & 0.77 & $11(2.6)$ \\
Psychological (P) & $4(1.8)$ & $6(2.7)$ & 0.75 & $10(2.2)$ \\
Others* & $12(5.4)$ & $10(4.6)$ & 0.76 & $22(4.9)$ \\
Total & $224(100)$ & $222(100)$ & & $446(100)$
\end{tabular}

*Ear $(\mathrm{H}) /$ endocrine, metabolic and nutritional $(\mathrm{T}) /$ pregnancy, childbearing, family planning $(\mathrm{W}) /$ female genital $(\mathrm{X}) /$ male genital $(\mathrm{Y}) /$ blood, blood forming organs and immune mechanism (B)

in a 51-year-old female passenger during the Shackleton walk, which is a strenuous expedition in the mountains of South Georgia. A dislocation of the inter-phalangeal joint was reduced ashore during an expedition walk in the Nunavut, Canada.

Ranked $4^{\text {th }}$ for the crewmembers and $9^{\text {th }}$ for the passenger, the mouth and dental diseases had a prevalence of $4.9 \%$ and $1.8 \%$, respectively ( $p=0.07$ ). These included acute periodontitis, acute pulpitis caused by tooth decay and cases of dental fractures.

Gastroenteritis that is a frightening condition on ships seemed to be more frequent in passengers than in crewmembers, who are usually aware of preventive measures that are emphasized and enforced on board (11.5\% vs. $5 \%$ of the infectious diagnoses), but the difference was not statistically significant $(p=0.10)$. One case of presumed bacterial gastroenteritis was diagnosed in one member of the crew coming from the Philippines. Nevertheless, it turned to be complicated by an allergic angioedema due to self-medication with non-steroidal anti-inflammatory drugs.

The most serious medical emergency was an acute gastrointestinal haemorrhage leading to repetitive loss of consciousness and bloody stools due to a duodenal ulcer experienced by one crewmember, while the ship was sailing through the Antarctic Peninsula. It required a medical evacuation from the Chilean Frei Station on King Georges Island, South Shetland, to save the patient.

The ophthalmologic issues were responsible for few consultations; however, eye diseases seemed to affect preferentially crewmembers, mainly affected by infectious diseases of the ocular appendages. A presumed bacterial keratitis evolving towards a corneal ulcer ap- peared in a crewmember during navigation to Antarctica on the Drake Passage. It was cured under local antibiotic therapy.

Finally neurological pathologies were significantly more frequent in passengers and included cases of seasickness. An epileptic seizure secondary to benign brain lesions occurred in one passenger.

\section{DISCUSSION}

Several parameters depending of the cruise duration and navigation area may come into play to outline the medical practice on board. Contrary to the present prospective study carried out on board a cruise ship during a sailing cruise around the world, with several stops [13], the previous reports were retrospective studies, based on data collected from the medical files of several cruise ships and focused on the passenger pathologies $[8,10,12,16]$. Herein, we studied the different pathologies encountered by the onboard population integrating passengers as well as staff, to better reflect the medical activity and the health status on an expedition ship in remote areas. Our work is based on the International Classification in Primary Care, $2^{\text {nd }}$ version [14]. This classification was used for the following three reasons: 1 ) the ship doctor, study investigator, had previously been trained to its practice for the study ECOGEN Respi [17] (consultations coding by ICPC-2) (16); 2) the use of ICPC-2 is efficient and facilitates data retrieval; 3) all medical specialties encountered in primary care and emergency medicine are represented. Therefore it seems the best suitable choice for the practice of medicine in remote area where emergencies and primary care are encountered. 
Table 3. Cumulative incidences of the first ten diagnoses in the crewmember population out of 222 diagnoses

\begin{tabular}{|c|c|c|c|}
\hline \multirow[t]{2}{*}{ Rank } & \multicolumn{2}{|c|}{ Medical diagnoses } & \multirow[t]{2}{*}{$n(/ 100)$} \\
\hline & $\begin{array}{l}\text { ICPC } \\
\text { coding }\end{array}$ & Diagnoses & \\
\hline 1 & $\mathrm{R} 74$ & Acute upper respiratory infection & $51(23)$ \\
\hline 2 & $\mathrm{~S} 88$ & Dermatitis contact/allergic & $16(7.2)$ \\
\hline 3 & $\mathrm{~S} 18$ & Laceration, cut & $13(5.8)$ \\
\hline 4 & D82 & Teeth/gum disease & $11(4.9)$ \\
\hline 5 & L84 & $\begin{array}{l}\text { Back syndrome with no } \\
\text { radiating pain }\end{array}$ & $9(4)$ \\
\hline 6 & R76 & Acute angina, tonsillitis & $7(3.1)$ \\
\hline \multirow[t]{3}{*}{7} & D83 & Mouth/tongue/lip disease & $6(2.7)$ \\
\hline & $\mathrm{R} 80$ & Influenza & \\
\hline & $\mathrm{S} 14$ & Burn/scald & \\
\hline \multirow[t]{2}{*}{8} & D73 & $\begin{array}{l}\text { Gastroenteritis presumed } \\
\text { infection }\end{array}$ & $5(2.2)$ \\
\hline & $\mathrm{F} 72$ & Blepharitis/stye/chalazion & \\
\hline \multirow[t]{4}{*}{9} & A92 & Allergy/allergic reaction & $4(1.8)$ \\
\hline & F91 & Refractive error & \\
\hline & L87 & Bursitis/tendinitis/synovitis & \\
\hline & $\mathrm{S} 10$ & Boil/carbuncle & \\
\hline \multirow[t]{10}{*}{10} & K96 & Haemorrhoids & $3(1.3)$ \\
\hline & L86 & $\begin{array}{l}\text { Back syndrome with radiating } \\
\text { pain }\end{array}$ & \\
\hline & L99 & Other musculoskeletal disease & \\
\hline & N99 & $\begin{array}{l}\text { Motion sickness (other neuro- } \\
\text { logical diseases) }\end{array}$ & \\
\hline & P74 & Anxiety disorder/anxiety state & \\
\hline & S03 & Warts & \\
\hline & $\mathrm{S} 17$ & Abrasion, scratch, blister & \\
\hline & $\mathrm{S} 74$ & Dermatophytosis & \\
\hline & U71 & Cystitis/other urinary infection & \\
\hline & W78 & Pregnancy & \\
\hline
\end{tabular}

First, it is worth noting that, compared to previous studies, the prevalence of seasickness in the present study may seem low $[10,12]$. This is certainly due to our criteria of inclusion. Indeed, most of the cases of seasickness were managed by the nurses and nurse consultations were not included in the study. Moreover, some drugs against seasickness were in open access at the ship reception.

As previously described, respiratory and digestive viruses including easily person-to-person transmitted viruses were still frequently encountered medical problems $[8,9$, $18,19]$. Contaminated passengers before embarking as well as crewmembers infected during stops ashore are vectors of
Table 4. Cumulative incidences of the first ten diagnoses in the passenger population out of 224 diagnoses

\begin{tabular}{|c|c|c|c|}
\hline \multirow[t]{2}{*}{ Rank } & \multicolumn{2}{|c|}{ Medical diagnoses } & \multirow[t]{2}{*}{$n(/ 100)$} \\
\hline & $\begin{array}{l}\text { ICPC-2 } \\
\text { coding }\end{array}$ & Diagnoses & \\
\hline 1 & R74 & Acute upper respiratory infection & $34(15.2)$ \\
\hline 2 & N99 & $\begin{array}{l}\text { Motion sickness (other neuro- } \\
\text { logical diseases) }\end{array}$ & $18(8)$ \\
\hline 3 & $\mathrm{R} 78$ & Acute bronchitis, bronchiolitis & $15(6.7)$ \\
\hline \multirow[t]{2}{*}{4} & S17 & Abrasion, scratch, blister & $12(5.4)$ \\
\hline & S18 & Laceration, cut & \\
\hline \multirow[t]{2}{*}{5} & D73 & $\begin{array}{l}\text { Gastroenteritis presumed } \\
\text { infection }\end{array}$ & $11(4.9)$ \\
\hline & L84 & $\begin{array}{l}\text { Back syndrome with no radiating } \\
\text { pain }\end{array}$ & \\
\hline 6 & K86 & Hypertension uncomplicated & 7 (3.1) \\
\hline 7 & R76 & Acute angina, tonsillitis & $6(2.7)$ \\
\hline \multirow[t]{2}{*}{8} & L77 & Sprain/strain of ankle & $5(2.2)$ \\
\hline & U71 & Cystitis/other urinary infection & \\
\hline \multirow[t]{4}{*}{9} & D82 & Teeth/gum disease & $4(1.8)$ \\
\hline & D84 & Oesophagus disease & \\
\hline & S76 & Other skin infection & \\
\hline & S88 & Dermatitis contact/allergic & \\
\hline \multirow[t]{6}{*}{10} & $\mathrm{~A} 02$ & Hypothermia (chills) & $3(1.3)$ \\
\hline & D83 & Mouth/tongue/lip disease & \\
\hline & D87 & Stomach function disorder & \\
\hline & L79 & Sprain/strain of joint & \\
\hline & P82 & Post-traumatic stress disorder & \\
\hline & T90 & Diabetes non-insulin dependent & \\
\hline
\end{tabular}

such infectious agents on board [18]. It is an identified but still major health concerns in cruise trip, which is difficult to counteract despite sanitary measures on board because the spread of viral infection can be extremely striking due to the close and frequent interactions between people [20, 21]. This particularly refers to crewmembers, who are often four per cabins and therefore are more likely to become infected. In the present study, the prevalence of gastroenteritis complaints, which is mainly driven by norovirus $[19,22$, 23], was low. According to the navigation area, the ship is subject to strict health inspections requiring the physician to notify all gastrointestinal infection and to respect cleaning protocols in case of outbreak. Each case is recorded in a specific register and managed according a specific policy including the patient isolation for 24 to 48 hours and cabins disinfection [19, 23]. The gastrointestinal infections have often a worst outcome in the elderly leading to acute dehydration with fluid and electrolyte deficits evolving towards 
an acute renal failure $[21,24]$. Moreover, the occurrence of such conditions can be amplified by seasickness-induced iterative vomiting [25].

Aboard, the incidence of cardiovascular diseases was higher in passengers due to their older average age. They occurred in patients with past medical history whose chronic pathologies may decompensate on board, often due to viral opportunistic infections, benign in a healthy person [18]. In addition, it is known that the ship's navigation areas have a direct impact on the risk of cardiovascular decompensation and large temperature fluctuations increase the occurrence of death. It is known that exposure to extreme cold increases the risk of cardiovascular diseases and cardiac arrest but also the risk for person with chronic obstructive pulmonary disease [26-29].

The importance of having access to passengers medical files before the cruise is necessary to prevent at best any medical decompensation. This may be even more important when the medical decompensation may potentially evolve to a condition requiring sophisticated medical care and/or urgent evacuation while navigating in polar areas outside helicopter range or in areas where it could be extremely difficult because of the arid climate. In our study, half the time, the ship was sailing on polar and remote areas. Climatic factors (strong wind and gusts, extreme cold and freezing), accessibility depending on sea ice conditions, runway availability, remoteness and obscurity, are limitations to a successful evacuation which may, therefore, be delayed for several days [2, 30, 31]. Norway has set up an airborne medical evacuation system from Svalbard (Spitzbergen) to Tromso on the mainland. Flights last more than 3 hours and are weather-dependent [4]. Medical evacuations in remote areas require an international coordination between various actors. During the time of our study, the effectiveness of the evacuation of a crewmember from the Antarctic Peninsula was appreciated [32]. An intense cooperation was performed between the French ship, the Chilean Frei Station and the Argentinian Air Force who flew to Rio Gallegos in Argentina. In 1979, one patient had also been evacuated from Antarctica due to gastrointestinal bleeding. This cooperation between the main actors had enabled the success of the evacuation [33].

Therefore, some effort should be dedicated to medical prevention before embarkation to avoid medical evacuations as much as possible. Moreover, in medical evacuation, the physician's role and responsibility are crucial. Such decision will obviously affect the cruise progress. While the physician on longer voyages must be prepared to handle this type of emergency, in agreement with the captain, we therefore believe that he should be allowed to deny boarding to any person with a compromised health condition jeopardizing safety on board, that may lead to a lethal situation.
Fortunately, in our study, no case of death was noticed while the risk was prominent in 2 patients who required a medical evacuation: 1 case of pneumonia with heart failure in a 91-year-old passenger during a cruise in the Chilean Fjords and 1 case of acute gastrointestinal haemorrhage during navigation in the Antarctic Peninsula. Our results confirmed the observation of previous studies showing that death on board is a rare event. No death was reported in Dahl's study in a 106-day voyage with 4244 patients [13]. Schutz's investigation reported one single death in 2366 passengers and out of 680 consultations during 26 Antarctica voyages [12]. Four deaths out of 1547 consultations were recorded in a study conducted on 19 voyages through the Caribbean sea (3627 persons aboard) [16] and 15 deaths out of 196,171 passengers in a retrospective work based on data regarding 172 cruises of an average length of 7.8 days aboard four cruise ships [8].

While it should surely be helpful to have access to copies of the medical files of the passengers, it is mandatory for the crewmember to possess a medical certificate for service at sea. It is interesting to note that dental diseases don't seem to prevent from obtaining such a certificate. In our study, the majority of crew has a low socio-economic status, often originating from the Philippines, Indonesia or Mauritius with a difficult access to health care in their country of origin. Therefore it is not surprising that the prevalence of dental disease were more prevalent (4.9\%) among them than in the passengers (1.8\%). The overall prevalence of $3.4 \%$ for the all population underlines the importance of not disregarding these dental pathologies that are mainly infectious and for which an evolution to an acute focal infection (such as cellulitis, phlegmon, abscess formation) that could evolve towards septicaemia and, rarely, endocarditis may be anticipated [34]. Accordingly, dental symptoms, such as acute pain or swelling, seriously alter the daily quality of life of passengers and crewmembers [1]. Therefore, some knowledge in dentistry would be very useful to the doctor to mitigate dental risks and alleviate suffering of the patient.

Finally, we observed a quite low prevalence of trauma that was similar to that of previous studies [8-10,12]. The ship operates in a constantly moving environment that movement depends on the sea conditions, which can be rough especially in the southern seas. It results in a greater risk of falls than on land; especially for passengers and elderlies who are not used to the ship movements and often have sensory impairment (disturbances in depth perception and contrast sensitivity are one of the risk factors) [35]. Landings ashore can occur over uneven ground, which increases the risk of accidental falls and traumas. Although it may seems intuitive that the risk may be greater for crewmembers working in a harsh environment, such as the engine room, the prevalence of traumas in this population 
was low. This can be explained by the strict compliance to safety instructions, wearing of helmets and safety shoes during work, reminding the importance of the onboard safety procedures.

\section{CONCLUSIONS}

Maritime medicine offers a rich and interesting medical practice for physicians as it integrates several fields of medicine and it proposes different types of doctor-patient relationship for the passengers and the crew. Indeed caring out the medical follow-up, especially of the staff, could lead to more familiar interaction, while providing emergency primary care in difficult conditions is also expected. This underlines that the physician should not only demonstrate professional (e.g. general medicine) competency but also acquire a broad range of personal skills that encompasses empathy, communication, time-management and decision-making. While the patient should perceive him as their "family physician", the ship's doctor will also have to face many responsibilities that are specific of cruise ship, especially regarding chain-ofcommand and procedure of emergency evacuation.

Therefore, it should be helpful to improve such skills, particularly on maritime subjects, through specific maritime medicine training. For instance, dental cares and outpatient surgery should be taught to ship's doctors before embarkation, as it was done for those who committed themselves to the French Southern and Antarctic Territories. In conclusion, the results of our epidemiological work should stimulate the development of medical protocols for ships lacking physician, on which the captain is responsible for medical care, describing the management of the pathologies we identified as the most frequently on board.

\section{REFERENCES}

1. Sobotta BAJ, John MT, Nitschke I. Dental practice during a world cruise: characterisation of oral health at sea. Int Marit Health. 2006; 57(1-4): 136-148, indexed in Pubmed: 17312702.

2. Prociv P. Health aspects of Antarctic tourism. J Travel Med. 1998; 5(4): 210-212, indexed in Pubmed: 9876197.

3. International Association of Antarctica Tour Operators. Tourism Statistics . http://iaato.org/tourism-statistics (30/07/2017).

4. Norum J. Cardiovascular disease (CVD) in the Norwegian Arctic. Air ambulance operations 1999-2009 and future challenges in the region. Int Marit Health. 2010; 62(3): 117-122, indexed in Pubmed: 21154297.

5. Turney C. This was no Antarctic pleasure cruise. Nature. 2014; 505(7482): 133, doi: 10.1038/505133a, indexed in Pubmed: 24402248.

6. Terres Australes et Antarctiques Françaises. Présentation générale des TAAF. http://www.taaf.fr/Presentation-generale-des-TAAF (30/07/2017).

7. Smith LC, Stephenson SR. New Trans-Arctic shipping routes navigable by midcentury. Proc Natl Acad Sci U S A. 2013; 110(13): E1191-E1195, doi:10.1073/pnas.1214212110, indexed in Pubmed: 23487747.
8. Peake DE, Gray CL, Ludwig MR, et al. Descriptive epidemiology of injury and illness among cruise ship passengers. Ann Emerg Med. 1999; 33(1): 67-72, indexed in Pubmed: 9867889.

9. Dahl E. Anatomy of a world cruise. J Travel Med. 1999; 6(3): 168-171, indexed in Pubmed: 10467153.

10. Bledsoe GH, Brill JD, Zak D, et al. Injury and illness aboard an Antarctic cruise ship. Wilderness Environ Med. 2007; 18(1): 36-40, indexed in Pubmed:17447712.

11. Pearson WS, Bhat-Schelbert K, Probst JC. Multiple chronic conditions and the aging of America: challenge for primary care physicians. J Prim Care Community Health. 2012; 3(1): 51-56, doi: 10.1177/2150131911414577, indexed in Pubmed: 23804855.

12. Schutz L, Zak D, Holmes JF. Pattern of passenger injury and illness on expedition cruise ships to Antarctica. J Travel Med. 2014; 21(4): 228-234, doi:10.1111/jtm.12126, indexed in Pubmed: 24831067.

13. Dahl E. Medical practice during a world cruise: a descriptive epidemiological study of injury and illness among passengers and crew. Int Marit Health. 2005; 56(1-4): 115-128, indexed in Pubmed: 16532590.

14. World Health Organization. International Classification of Primary Care, Second Edition (ICPC-2). http://www.who.int/classifications/ icd/adaptations/icpc2/en/ (30/07/2017).

15. Ressiot E, Dolz M, Bonne L, et al. Étude prospective sur l'efficacité de la rééducation optocinétique dans le traitement des naupathies. Annales françaises d'Oto-rhino-laryngologie et de Pathologie Cervico-faciale. 2013; 130(5): 268-273, doi: 10.1016/j. aforl.2013.02.010.

16. DiGiovanna T, Rosen T, Forsett R, et al. Shipboard medicine: a new niche for emergency medicine. Ann Emerg Med. 1992; 21(12): 1476-1479, indexed in Pubmed: 1443847.

17. Carron M, Van Gy, Fuzibet JG, et al. ECOGEN RESPI: étude des résultats de consultation associés à un motif respiratoire en médecine générale. Exercer. 2015; 26(118): 61-67.

18. Brotherton JML, Delpech VC, Gilbert GL, et al. Cruise Ship Outbreak Investigation Team. A large outbreak of influenza A and B on a cruise ship causing widespread morbidity. Epidemiol Infect. 2003; 130(2): 263-271, indexed in Pubmed: 12729195.

19. Cramer EH, Blanton CJ, Blanton LH, et al. Vessel Sanitation Program Environmental Health Inspection Team. Epidemiology of gastroenteritis on cruise ships, 2001-2004. Am J Prev Med. 2006; 30(3): 252-257, doi: 10.1016/j.amepre.2005.10.027, indexed in Pubmed: 16476642.

20. White MB, Rajagopalan S, Yoshikawa TT. Infectious Diarrhea: Norovirus and Clostridium difficile in Older Adults. Clin Geriatr Med. 2016; 32(3): 509-522, doi: 10.1016/j.cger.2016.02.008, indexed in Pubmed: 27394020.

21. DuPont HL. Acute infectious diarrhea in immunocompetent adults. N Engl J Med. 2014; 370(16): 1532-1540, doi: 10.1056/NEJMra1301069, indexed in Pubmed: 24738670.

22. Isakbaeva ET, Widdowson MA, Beard RS, et al. Norovirus transmission on cruise ship. Emerg Infect Dis. 2005; 11(1): 154-158, doi:10.3201/eid1101.040434, indexed in Pubmed: 15705344.

23. Freeland AL, Vaughan GH, Banerjee SN. Acute Gastroenteritis on Cruise Ships - United States, 2008-2014. MMWR Morb Mortal Wkly Rep. 2016; 65(1): 1-5, doi: 10.15585/mmwr.mm6501a1, indexed in Pubmed: 26766396.

24. Trivedi TK, DeSalvo T, Lee L, et al. Hospitalizations and mortality associated with norovirus outbreaks in nursing homes, 2009-2010. JAMA. 2012; 308(16): 1668-1675, doi: 10.1001/ jama.2012.14023, indexed in Pubmed: 23079758. 
25. Golding JF. Motion Sickness. Handb Clin Neurol. 2016; 137: 371-90.

26. Madrigano J, Mittleman MA, Baccarelli A, et al. Temperature, myocardial infarction, and mortality: effect modification by individual- and area-level characteristics. Epidemiology. 2013; 24(3): 439-446, doi: 10.1097/EDE.0b013e3182878397, indexed in Pubmed: 23462524.

27. Medina-Ramón M, Zanobetti A, Cavanagh DP, et al. Extreme temperatures and mortality: assessing effect modification by personal characteristics and specific cause of death in a multi-city case-only analysis. Environ Health Perspect. 2006; 114(9): 1331-1336, indexed in Pubmed: 16966084.

28. Näyhä S. Environmental Temperature and Mortality. Int J Circumpolar Health. 2005; 64(5): 4518.

29. Schwartz J. Who is sensitive to extremes of temperature?: A case-only analysis. Epidemiology. 2005; 16(1): 67-72, indexed in Pubmed: 15613947.

30. Mills $\mathrm{CN}$, Mills GH, Mills GH, et al. Challenges of air medical evacuation from Antarctica. Air Med J. 2008; 27(6):
281-285, doi:10.1016/j.amj.2008.07.009, indexed in Pubmed: 18992687.

31. Dahl E. Medical cruise challenges in Antarctica. J Travel Med. 2014; 21(4): 223-224, doi: 10.1111/jtm.12118, indexed in Pubmed: 24980124.

32. Carron M, Globokar P, Sicard BA. Acute gastrointestinal haemorrhage on board a cruise ship in the Antarctic Peninsula. Int Marit Health. 2016; 67(4): 223-226, doi: 10.5603/IMH.2016.0040, indexed in Pubmed: 28009388.

33. Podkolinski MT, Semmens K. Intestinal haemorrhage in Antarctica. A multinational rescue operation. Med J Aust. 1979; 2(6): 275-277, indexed in Pubmed: 522753.

34. Olsen I, van Winkelhoff AJ. Acute focal infections of dental origin. Periodontol 2000. 2014; 65(1): 178-189, doi: 10.1111/prd.12018, indexed in Pubmed:24738592.

35. Khow KSF, Visvanathan R. Falls in the aging population. Clin Geriatr Med. 2017; 33(3): 357-368, doi: 10.1016/j.cger.2017.03.002, indexed in Pubmed:28689568. 